\title{
A Família e a Escola como contextos de desenvolvimento humano
}

\author{
Maria Auxiliadora Dessen \\ Ana da Costa Polonia \\ Universidade de Brasília, Distrito Federal, Brasil
}

\begin{abstract}
Resumo: Escola e família constituem dois contextos de desenvolvimento fundamentais para a trajetória de vida das pessoas. Neste artigo, são destacadas as contribuições destes contextos para a promoção do desenvolvimento humano, enfatizando suas implicações nos processos evolutivos. Questões sobre configurações, vínculos familiares e a importância da rede social de apoio para o desenvolvimento da família são discutidas. Focalizam-se as funções da escola, considerando sua influência nas pessoas em desenvolvimento. Apontam-se algumas considerações sobre a necessidade de compreender as inter-relações entre escola e família, visando facilitar a aprendizagem e desenvolvimento humano. A integração entre esses dois contextos é destacada como desafio para a prática profissional e pesquisa empírica.
\end{abstract}

Palavras-chave: Família. Escola. Desenvolvimento humano.

\section{Family and School as context for human development}

\begin{abstract}
School and family constitute two developmental contexts essential for the lifespan trajectories. In this article, it is highlighted the contribution of both contexts to human development promotion, emphasizing their implications on evolutionary processes. The issues about family links, configurations, and the importance of the social support network for family development are discussed. The school functions are focused considering their influences on developing persons. Considerations are also made about the necessity of understanding the inter-relations between the school and the family, aiming to promote learning and human development. The integration between these two contexts is a challenge for both the professional practice and the empirical research.
\end{abstract}

Keywords: Family. School. Human development.

\section{La Familia y la Escuela como contextos del desarrollo humano}

Resumen: La escuela y la familia constituyen dos contextos del desarrollo fundamentales para la historia de vida de las personas. Resaltamos las contribuciones de ambos contextos para la promoción del desarrollo humano, enfatizando sus implicaciones en los procesos evolutivos. Discutimos cuestiones sobre las configuraciones y vínculos familiares y la importancia de la red social de apoyo para el desarrollo de la familia. Enfatizamos las funciones de la escuela, considerando su influencia sobre el desarrollo de las personas. Apuntamos la necesidad de comprender las interrelaciones entre la escuela y la familia, visando facilitar el aprendizaje y el desarrollo humano. La integración entre estos dos contextos es destacada como un desafio tanto para la práctica profesional como para las investigaciones empíricas.

Palabras clave: Familia. Escuela. Desarrollo humano. 
A escola e a família compartilham funções sociais, políticas e educacionais, na medida em que contribuem e influenciam a formação do cidadão (Rego, 2003). Ambas são responsáveis pela transmissão e construção do conhecimento culturalmente organizado, modificando as formas de funcionamento psicológico, de acordo com as expectativas de cada ambiente. Portanto, a família e a escola emergem como duas instituições fundamentais para desencadear os processos evolutivos das pessoas, atuando como propulsoras ou inibidoras do seu crescimento físico, intelectual, emocional e social. Na escola, os conteúdos curriculares asseguram a instrução e apreensão de conhecimentos, havendo uma preocupação central com o processo ensino-aprendizagem. Já, na família, os objetivos, conteúdos e métodos se diferenciam, fomentando o processo de socialização, a proteção, as condições básicas de sobrevivência e o desenvolvimento de seus membros no plano social, cognitivo e afetivo.

A integração entre escola e família tem despertado, recentemente, o interesse dos pesquisadores (Davies, Marques \& Silva, 1997; Marques, 2002; Oliveira \& cols., 2002), principalmente no que se refere às implicações deste envolvimento para o desenvolvimento social e cognitivo e o sucesso escolar do aluno. Neste artigo, os ambientes familiar e escolar são descritos como contextos de desenvolvimento humano, ressaltando a importância do estabelecimento de relações apropriadas entre ambos. A primeira seção trata da família e de seu espaço como agente socializador, enfatizando aspectos relacionados às configurações familiares, à rede social de apoio e aos vínculos familiares e suas implicações para o desenvolvimento humano. Na segunda seção, a escola é destacada como um contexto de desenvolvimento, priorizando uma reflexão sobre sua função social, as suas tarefas e papéis na sociedade contemporânea, especificamente no que diz respeito ao cenário político-pedagógico. A terceira seção apresenta argumentos na direção de estimular o envolvimento entre a família e a escola. E enfatiza-se a necessidade de envidar esforços para melhor compreender as relações família-escola, de modo a assegurar que ambos os contextos sejam espaços efetivos para a aprendizagem e o desenvolvimento humano.

\section{A Família como contexto de desenvolvimento humano}

A família, presente em todas as sociedades, é um dos primeiros ambientes de socialização do indivíduo, atuando como mediadora principal dos padrões, modelos e influências culturais (Amazonas, Damasceno, Terto \& Silva, 2003; Kreppner, 1992, 2000). É também considerada a primeira instituição social que, em conjunto com outras, busca assegurar a continuidade e o bem estar dos seus membros e da coletividade, incluindo a proteção e o bem estar da criança. A família é vista como um sistema social responsável pela transmissão de valores, crenças, idéias e significados que estão presentes nas sociedades (Kreppner, 2000). Ela tem, portanto, um impacto significativo e uma forte influência no comportamento dos indivíduos, especialmente das crianças, que aprendem as diferentes formas de existir, de ver o mundo e construir as suas relações sociais.

Como primeira mediadora entre o homem e a cultura, a família constitui a unidade dinâmica das relações de cunho afetivo, social e cognitivo que estão imersas nas condições materiais, históricas e culturais de um dado grupo social. Ela é a matriz da aprendizagem humana, com significados e práticas culturais próprias que geram modelos de relação interpessoal e de construção individual e coletiva. Os acontecimentos e as experiências familiares propiciam a formação de repertórios comportamentais, de ações e resoluções de problemas com significados universais (cuidados com a infância) e particulares (percepção da escola para uma determinada família). Essas vivências integram a experiência coletiva e individual que organiza, interfere e a torna uma unidade dinâmica, estruturando as formas de subjetivação e interação social. E é por meio das interações familiares que se concretizam as transformações nas sociedades que, por sua vez, influenciarão as relações familiares futuras, caracterizando-se por um processo de influências bidirecionais, entre os membros familiares e os diferentes ambientes que compõem os sistemas sociais, dentre eles a escola, constituem fator preponderante para o desenvolvimento da pessoa.

Portanto, as transformações tecnológicas, sociais e econômicas favorecem as mudanças na es- 
trutura, organização e padrões familiares e, também, nas expectativas e papéis de seus membros. E a constituição e a estrutura familiar, por sua vez, afetam diretamente a elaboração do conhecimento e as formas de interação no cotidiano das famílias (Amazonas \& cols., 2003; Campos \& Francischini, 2003). Portanto, ela é a principal responsável por incorporar as transformações sociais e intergeracionais ocorridas ao longo do tempo, com os pais exercendo um papel preponderante na construção da pessoa, de sua personalidade e de sua inserção no mundo social e do trabalho (Távora, 2003; Volling \& Elins, 1998).

No ambiente familiar, a criança aprende a administrar e resolver os conflitos, a controlar as emoções, a expressar os diferentes sentimentos que constituem as relações interpessoais, a lidar com as diversidades e adversidades da vida (Wagner, Ribeiro, Arteche \& Bornholdt, 1999). Essas habilidades sociais e sua forma de expressão, inicialmente desenvolvidas no âmbito familiar, têm repercussões em outros ambientes com os quais a criança, o adolescente ou mesmo $\mathrm{o}$ adulto interagem, acionando aspectos salutares ou provocando problemas e alterando a saúde mental e física dos indivíduos (Del Prette \& Del Prette, 2001).

\section{A Família e suas configurações}

Os membros de famílias contemporâneas têm se deparado e adaptado às novas formas de coexistência oriundas das mudanças nas sociedades, isto é, do conflito entre os valores antigos e o estabelecimento de novas relações (Chaves, Cabral, Ramos, Lordelo \& Mascarenhas, 2002). Como parte de um sistema social, englobando vários subsistemas, os papéis dos seus membros são estabelecidos em função dos estágios de desenvolvimento do indivíduo e da família vista enquanto grupo (Dessen, 1997; Kreppner, 1992, 2000). Por exemplo, ser adolescente crescendo em uma família 'nuclear tradicional', com irmãos biológicos, é diferente de sê-lo em uma família recasada, coabitando com padrasto e irmãos não biológicos.

Sendo composta por uma complexa e dinâmica rede de interações que envolve aspectos cognitivos, sociais, afetivos e culturais, a família não pode ser definida apenas pelos laços de consangüinidade, mas sim por um conjunto de variáveis incluindo o significado das interações e relações entre as pessoas
(Petzold, 1996). A própria concepção científica dela evidencia o entrelaçamento das variáveis biológicas, sociais, culturais e históricas que exercem grande influência nas relações familiares, constituindo a base para as formas contemporâneas dela. Os laços de consangüinidade, as formas legais de união, o grau de intimidade nas relações, as formas de moradia, o compartilhamento de renda são algumas dessas variáveis que, combinadas, permitem a identificação de 196 tipos de famílias, produto de cinco subsistemas resultantes da concepção ecológica de micro, meso, exo, macro e cronossistema (Petzold, 1996).

De acordo com a concepção proposta por Petzold (1996), a combinação derivada do microssistema tem como base as relações diádicas, isto é, como os genitores interagem, com destaque para o grau de intimidade: se o estilo de vida é compartilhado ou separado, se esta relação é considerada heterossexual ou homossexual, se há alteridade no poder ou não. Já aquelas influências provenientes do mesossistema compreendem as relações com os filhos, ou seja, a sua presença ou ausência, se eles são biológicos ou adotivos e se moram com os pais ou não.

No tocante ao exossistema do grupo familiar, esse engloba os contextos e as redes sociais que asseguram o sentimento de pertencer a um grupo especial, social ou cultural, tais como as relações mantidas por laços de consangüinidade ou casamento, vínculos de dependência ou autonomia financeira ou emocional. E o macrossistema reflete os valores e as crenças compartilhadas por um conjunto de pessoas, por exemplo, relacionadas ao fato de a união ser civil ou não, de a relação ser estável ou temporária, de os cônjuges habitarem ou não o mesmo espaço físico. E, por fim, o cronossistema diz respeito às transformações da família na sociedade, incluindo as suas diferentes configurações ao longo do tempo, dentre as quais a família extensa e a monoparental.

O próprio conceito de família e a configuração dela têm evoluído para retratar as relações que se estabelecem na sociedade atual. Não existe uma configuração familiar ideal, porque são inúmeras as combinações e formas de interação entre os indivíduos que constituem os diferentes tipos de famílias contemporâneas (Stratton, 2003): nuclear tradicional, recasadas, monoparentais, homossexuais, dentre ou- 
tras combinações. Os padrões familiares vão se transformando e reabsorvendo as mudanças psicológicas, sociais, políticas, econômicas e culturais, o que requer adaptações e acomodações às realidades enfrentadas (Wagner, Halpern \& Bornholdt, 1999). E, os arranjos familiares distintos que vão surgindo, por sua vez, provocam transformações nas relações familiares, nos papéis desempenhados pelos seus membros, nos valores, nas funções intergeracionais, nas expectativas e nos processos de desenvolvimento do indivíduo.

Portanto, a família, hoje, não é mais vista como um sistema privado de relações; ao contrário, as atividades individuais e coletivas estão intimamente ligadas e se influenciam mutuamente. O que ocorre na família e na sociedade é sintetizado, elaborado e modificado provocando a evolução e atualização dela e de sua história na sociedade (Kreppner, 1992). A família também é a responsável pela transmissão de valores culturais de uma geração para outra. Essa transmissão de conhecimentos e significados possibilita o compartilhar de regras, valores, sonhos, perspectivas e padrões de relacionamentos, bem como a valorização do potencial dos seus membros e de suas habilidades em acumular, ampliar e diversificar as experiências. De acordo com Kreppner (2000), a família e suas redes de interações asseguram a continuidade biológica, as tradições, os modelos de vida, além dos significados culturais que são atualizados e resgatados, cronologicamente.

Ao desempenhar suas funções, dentre as quais a socialização da criança, a família estabelece uma estrutura mínima de atividades e relações em que os papéis de mãe, pai, filho, irmão, esposa, marido, e outros são evidenciados. Todavia, a formação dos vínculos afetivos não é imutável, pelo contrário, ela vai se diferenciando e progredindo mediante as modificações do próprio desenvolvimento da pessoa, as demandas sociais e as transformações sofridas pelo grupo sócio-cultural (Kreppner, 2000). De acordo com este autor, além de se adaptar às mudanças decorrentes do crescimento dos seus membros, a família ainda tem a tarefa de manter o bem estar psicológico de cada um, buscando sempre nova estabilidade nas relações familiares.
Neste processo contínuo de busca por estabilidade, as famílias contam ou não com o suporte de uma rede social de apoio, que permite a elas superarem (ou não) as dificuldades decorrentes de transições do desenvolvimento (Dessen \& Braz, 2000). Independente das que ocorrem no âmbito familiar, elas são produtoras de mudanças que podem funcionar como aspectos propulsores ou inibidores do desenvolvimento, influenciando, direta ou indiretamente, os modos de criação dos filhos. No entanto, a principal rede de apoio da família é oriunda das próprias interações entre seus membros. Contatos negativos, conflitos, rompimentos e insatisfações podem gerar problemas futuros, particularmente nas crianças. Por outro lado, relações satisfatórias e felizes entre maridoesposa constituem fonte de apoio para ambos os cônjuges, sobretudo para a mulher (Dessen \& Braz, 2005).

Vínculos familiares e redes de apoio: implicações para o desenvolvimento

Os laços afetivos formados dentro da família, particularmente entre pais e filhos, podem ser aspectos desencadeadores de um desenvolvimento saudável e de padrões de interação positivos que possibilitam o ajustamento do indivíduo aos diferentes ambientes de que participa. Por exemplo, o apoio parental, em nível cognitivo, emocional e social, permite à criança desenvolver repertórios saudáveis para enfrentar as situações cotidianas (Eisenberg \& cols., 1999). Por outro lado, esses laços afetivos podem dificultar o desenvolvimento, provocando problemas de ajustamento social (Booth, Rubin \& Rose-Krasnor, 1998). Volling e Elins (1998) mostraram que o estresse parental, a insatisfação familiar e a incongruência nas atitudes dos pais em relação à criança geram problemas de ajustamento e dificuldades de interação social.

As figuras parentais exercem grande influência na construção dos vínculos afetivos, da auto-estima, autoconceito e, também, constroem modelos de relações que são transferidos para outros contextos e momentos de interação social (Volling \& Elins, 1998). Por exemplo, pais punitivos e coercitivos podem provocar em seus filhos comportamentos de insegurança, dificuldades de estabelecer e manter vínculos com outras crianças, além de problemas de risco social na escola e na vida adulta. Booth e cols (1998) investigaram o apoio social e emocional de mães e de ou- 
tras pessoas envolvidas com a criança e suas repercussões na adolescência e vida adulta. Eles observaram que a qualidade da relação mãe-criança é transferida, posteriormente, para outras relações interpessoais, na escola e no grupo de amigos. Paralelamente, identificaram que a qualidade da relação com os pares e amigos pode compensar a baixa qualidade de interação com as mães.

Os laços afetivos asseguram o apoio psicológico e social entre os membros familiares, ajudando no enfrentamento do estresse provocado por dificuldades do cotidiano (Oliveira \& Bastos, 2000). E os padrões de relações familiares relacionam-se intrinsecamente a uma rede de apoio que possa ser ativada, em momentos críticos, fomentando o sentimento de pertença, a busca de soluções e atividades compartilhadas.

No entanto, nem sempre as famílias constituem uma rede de apoio funcional e satisfatória ou, mesmo, melhor que outras. Dell' Aglio e Hutz (2002) compararam estratégias de enfrentamento entre crianças institucionalizadas e as que viviam com suas famílias e não encontraram diferenças nas de busca de apoio social e ação agressiva. Segundo os autores, muitas vezes, as instituições têm condições físicas, materiais e organizacionais e contam com profissionais e rotinas que estabelecem uma rede social de apoio forte e adequada. Portanto, o desenvolvimento de estratégias de enfrentamento apropriadas é influenciado pela qualidade das relações afetivas, coesão, segurança, ausência de discórdia e organização, quer na família ou na instituição. Tais aspectos constituem importantes fatores de proteção para o indivíduo, favorecendo o desenvolvimento de habilidades e competências sociais e, conseqüentemente, sua capacidade de adaptação às situações cotidianas (Chaves, Guirra, Borrione \& Simões, 2003).

Diante dos problemas e desafios enfrentados pela família, e sem uma rede de apoio social que promova a superação do estresse, a resolução de conflitos e o restabelecimento de uma dinâmica familiar saudável, as famílias podem desenvolver padrões de relacionamento disfuncionais, tais como: maus tratos à criança, violência intrafamiliar, abuso de substâncias, conflitos. Nesses casos, as instituições públicas ou privadas, incluindo a escola, têm um papel importante oferecendo apoio, direta ou indiretamente, por meio de programas de educação familiar (Dessen \& Pereira-Silva, 2004) ou de elaboração de políticas públicas para a promoção da saúde. Estas devem considerar os fatores de estresse e estimular a formação de redes de apoio social, seja na própria comunidade ou nos centros de atendimento à população, seja na escola, já que esta ocupa um lugar de destaque nas sociedades contemporâneas.

\section{A escola como contexto de desenvolvimento humano}

A escola constitui um contexto diversificado de desenvolvimento e aprendizagem, isto é, um local que reúne diversidade de conhecimentos, atividades, regras e valores e que é permeado por conflitos, problemas e diferenças (Mahoney, 2002). É nesse espaço físico, psicológico, social e cultural que os indivíduos processam o seu desenvolvimento global, mediante as atividades programadas e realizadas em sala de aula e fora dela (Rego, 2003). O sistema escolar, além de envolver uma gama de pessoas, com características diferenciadas, inclui um número significativo de interações contínuas e complexas, em função dos estágios de desenvolvimento do aluno. Trata-se de um ambiente multicultural que abrange também a construção de laços afetivos e preparo para inserção na sociedade (Oliveira, 2000).

\section{A escola e sua função social}

A escola emerge, portanto, como uma instituição fundamental para o indivíduo e sua constituição, assim como para a evolução da sociedade e da humanidade (Davies \& cols., 1997; Rego, 2003). Como um microssistema da sociedade, ela não apenas reflete as transformações atuais como também tem que lidar com as diferentes demandas do mundo globalizado. Uma de suas tarefas mais importantes, embora difícil de ser implementada, é preparar tanto alunos como professores e pais para viverem e superarem as dificuldades em um mundo de mudanças rápidas e de conflitos interpessoais, contribuindo para o processo de desenvolvimento do indivíduo.

Coerente com essa concepção, à escola compete propiciar recursos psicológicos para a evolução intelectual, social e cultural do homem (Hedeggard, 2002; Rego, 2003). Ao desenvolver, por meio de atividades sistemáticas, a articulação dos conhecimen- 
tos culturalmente organizados, ela possibilita a apropriação da experiência acumulada e as formas de pensar, agir e interagir no mundo, oriundas dessas experiências. Concomitantemente, ela proporciona o emprego da linguagem simbólica, a apreensão dos conteúdos acadêmicos e compreensão dos mecanismos envolvidos no funcionamento mental, fundamentais ao processo de aprendizagem. Assim, a atualização do conhecimento cultural e sua organização constante são premissas importantes para entender o papel dela e sua relação com a pessoa em desenvolvimento.

A escola é uma instituição social com objetivos e metas determinadas, que emprega e reelabora os conhecimentos socialmente produzidos, com o intuito de promover a aprendizagem e efetivar o desenvolvimento das funções psicológicas superiores: memória seletiva, criatividade, associação de idéias, organização e seqüência de conhecimentos, dentre outras (Oliveira, 2000). Ela é um espaço em que o indivíduo tende a funcionar de maneira preditiva, pois, em sala de aula, há momentos e atividades que são estruturados com objetivos programados e outros mais informais que se estabelecem na interação da pessoa com seu ambiente social. Por exemplo, na escola, o aluno tem rotinas como hora do intervalo e do lanche, em que os objetivos educacionais se dirigem à convivência em grupo e à inserção na coletividade. No tocante às atividades acadêmicas, espera-se, por exemplo, que os alunos dominem a interpretação, as regras fundamentais para expressão oral e escrita e realizem cálculos de forma independente.

O currículo escolar estabelece objetivos e atividades, conforme a série dos alunos, facilitando o acompanhamento do processo de ensino-aprendizagem nas diferentes faixas etárias. Desde o maternal até a educação de adultos, a escola tem peculiaridades em relação à sua estrutura física, à organização dos conteúdos e metodologias de ensino, respeitando e considerando a evolução do aprendiz, bem como articulando os conhecimentos científicos às experiências dos alunos. Por exemplo, no ensino médio, espera-se que o aluno apresente um raciocínio hipotético-dedutivo, demonstre autonomia nos estudos e pesquisas, enquanto que, no fundamental, os objetivos se dirigem ao domínio das operações complexas, empregando materiais concretos e experiências advindas do contexto familiar do aluno (Ministério da Educação, Secretaria de Educação Fundamental, 2001).

Marques (2001) destaca que a função da escola no século XXI tem o objetivo precípuo de estimular o potencial do aluno, levando em consideração as diferenças socioculturais em prol da aquisição do seu conhecimento e desenvolvimento global. Sob este prisma, ele aponta três objetivos que são comuns e devem ser buscados pelas escolas modernas: (a) estimular e fomentar o desenvolvimento em níveis físico, afetivo, moral, cognitivo, de personalidade; (b) desenvolver a consciência cidadã e a capacidade de intervenção no âmbito social; (c) promover uma aprendizagem de forma contínua, propiciando, ao aluno, formas diversificadas de aprender e condições de inserção no mercado de trabalho. Isto implica, necessariamente, em promover atividades ligadas aos domínios afetivo, motor, social e cognitivo, de forma integrada à trajetória de vida da pessoa.

Marques (2001) enfatiza também a importância das tarefas desempenhadas em sala de aula que favorecem as formas superiores de pensar e aprender, tais como memória seletiva, criatividade, raciocínio abstrato, pensamento lógico, tendo o professor uma função preponderante nesta mediação. Para Wallon, a idéia da mediação do conhecimento realizada pelo professor, por meio de materiais concretos, padrões e modelos de aprendizagem e comportamento, permitem que, na sala de aula, se incorpore uma ação coletiva que se estrutura e funciona graças ao uso de estratégias específicas, como o trabalho em grupo e aos pares e a realização de atividades recreativas, competitivas e jogos (Almeida, 2000).

No entanto, o uso de estratégias deve ser adaptado às realidades distintas dos alunos e professores, às demandas da comunidade e aos recursos disponíveis, levando em conta as condições e peculiaridades de cada época ou momento histórico. Neste sentido, é importante identificar as condições evolutivas dos segmentos: professores, alunos, pais e comunidade, em geral, para o planejamento de atividades no âmbito da escola.

Em síntese, a escola é uma instituição em que se priorizam as atividades educativas formais, sendo identificada como um espaço de desenvolvimento e 
aprendizagem e o currículo, no seu sentido mais amplo, deve envolver todas as experiências realizadas nesse contexto. Isto significa considerar os padrões relacionais, aspectos culturais, cognitivos, afetivos, sociais e históricos que estão presentes nas interações e relações entre os diferentes segmentos. Dessa forma, os conhecimentos oriundos da vivência familiar podem ser empregados como mediadores para a construção dos conhecimentos científicos trabalhados na escola.

\section{Compreendendo as relações família-escola}

Para compreender os processos de desenvolvimento e seus impactos na pessoa, é preciso focalizar tanto o contexto familiar quanto o escolar e suas inter-relações (Polonia \& Dessen, 2005). Por exemplo, o planejamento de pesquisa sobre violência na adolescência deve incluir tanto as variáveis familiares, que podem contribuir significativamente para a manutenção de comportamentos anti-sociais na escola, quanto as relacionadas diretamente com a escola, como o baixo desempenho acadêmico, que, aliadas aos fatores interpessoais, acentuam este problema (Ferreira \& Marturano, 2002; Oliveira \& cols., 2002).

Outros exemplos bastante conhecidos são a evasão e repetência escolar. Sabe-se que a estrutura familiar tem um forte impacto na permanência do aluno na escola, podendo evitar ou intensificar a evasão e a repetência escolar. Dentre os aspectos que contribuem para isto estão as características individuais, a ausência de hábitos de estudo, a falta às aulas e os problemas de comportamento (Fitzpatrick \& Yoles, 1992). Em todos estes fatores, a família exerce uma poderosa influência. Embora um sistema escolar transformador possa reverter esses aspectos negativos, faz-se necessário que a escola conte com a colaboração de outros contextos que influenciam significativamente a aprendizagem formal do aluno, incluindo a família (Fantuzzo, Tighe \& Childs, 2000).

É importante ressaltar que a família e a escola são ambientes de desenvolvimento e aprendizagem humana que podem funcionar como propulsores ou inibidores dele. Estudar as relações em cada contexto e entre eles constitui fonte importante de informação, na medida em que permite identificar aspectos ou condições que geram conflitos e ruídos nas comu- nicações e, conseqüentemente, nos padrões de colaboração entre eles. Nesta direção, é importante observar como a escola e, especificamente, os professores empregam as experiências que os alunos têm em casa. Face à leitura, é muito importante que a escola conheça e saiba como utilizar as experiências de casa para gerir as competências imprescindíveis ao letramento. A interpretação de textos ou a escrita podem ser estimuladas pelos conhecimentos oriundos de outros contextos, servindo de auxílio à aprendizagem formal.

As pesquisas têm demonstrado que os pais estão constantemente preocupados e envolvidos com as atividades escolares dos filhos e que dirigem a sua atenção à avaliação do aproveitamento escolar, sendo isto independente do nível socioeconômico ou escolaridade (Polonia \& Dessen, 2005). Os pais supervisionam e acompanham não somente a realização das atividades escolares, mas também adotam, em suas residências, estratégias voltadas à disciplina e ao controle de atividades lúdicas. Estas ações permitem a eles analisarem, identificarem e realizarem intervenções nos processos de desenvolvimento e aprendizagem dos filhos (Sanders \& Epstein, 1998). Ainda, neste aspecto, Epstein (citado por Marques, 2002) destaca o envolvimento dos pais em atividades, em casa, que afetam a aprendizagem e o aproveitamento escolar. Este envolvimento ocorre sob diferentes formas de acompanhamento das tarefas (monitorar a sua realização), ou, ainda, em orientações sistemáticas do comportamento social e engajamento dos filhos nas atividades da escola, realizadas por iniciativa própria ou por sugestão da escola.

Os laços afetivos, estruturados e consolidados tanto na escola como na família permitem que os indivíduos lidem com conflitos, aproximações e situações oriundas destes vínculos, aprendendo a resolver os problemas de maneira conjunta ou separada. Nesse processo, os estágios diferenciados de desenvolvimento, característicos dos membros da família e também dos segmentos distintos da escola, constituem fatores essenciais na direção de provocar mudanças nos papéis da pessoa em desenvolvimento, com repercussões diretas na sua experiência acadêmica e psicológica; dependendo do nível de desenvolvimento e demandas do contexto, é possibilitado à criança, 
quando entra na escola, um maior grau de autonomia e independência comparado ao que tinha em casa, o que amplia seu repertório social e círculo de relacionamento. Neste caso, a escola oferece uma oportunidade de exercitar um novo papel que propiciará mecanismos importantes para o seu desenvolvimento cognitivo, social, físico e afetivo, distintos do ambiente familiar.

Um outro aspecto a ser destacado nas pesquisas e programas é a formação das redes sociais de apoio. Deve-se, então, caracterizar as dimensões distintas de envolvimento, seja na família ou na escola, e descrever como e quando essa rede de relações e apoio à pessoa em desenvolvimento pode ser utilizada. Na família, há o reconhecimento do papel dos pais, irmãos e outras pessoas que convivem com a criança ou adolescente e sua contribuição para o desenvolvimento geral e acadêmico. Na escola, destacam-se os professores e os pares, uma vez que estes se envolvem cotidianamente em atividades programadas e realizam intervenções importantes que afetam o processo de ensino e aprendizagem. Considerando que as redes de apoio são constituídas pela diversidade de interações entre as pessoas, são estas que permitem a construção de repertórios para lidar com as adversidades e problemas surgidos, possibilitando sua superação com sucesso (Ferreira \& Marturano, 2002).

No tocante à colaboração escola-família, é importante enfatizar a necessidade de estruturar atividades apropriadas à série do aluno, particularmente em se tratando da participação dos pais no seu acompanhamento. Segundo Desland e Bertrand (2005), a necessidade ou não de supervisão aos filhos depende das demandas implícitas ou explícitas deles que, por sua vez, estão relacionadas a fatores como idade, independência, autonomia e desempenho como aluno. Esses autores vão além, afirmando que, ao participarem, os pais se predispõem e sentem referendados pelos filhos, acionando recursos que envolvem a ajuda e o acompanhamento; quando os filhos mostram necessidade de trabalharem sozinhos, os pais se afastam, reduzindo seu nível de supervisão e auxílio às tarefas escolares. Esta é uma questão polêmica que requer investigações mais detalhadas, considerando a série do aluno, as competências exigidas pela escola e a necessidade de autonomia e independência do aluno.
Apesar dos esforços, tanto da escola quanto da família, em promoverem ações de continuidade, há barreiras que geram descontinuidade e conflitos na integração entre estes dois microssistemas. Uma das dificuldades na integração família-escola é que esta ainda não comporta, em seus espaços acadêmicos, sociais e de interação, os diferentes segmentos da comunidade e, por isso, não possibilita uma distribuição eqüitativa das competências e o compartilhar das responsabilidades. Carneiro (2003) afirma que a mudança deste paradigma depende de uma transformação na cultura vigente da escola e que o projeto político-pedagógico poderia ser um dos meios para promover esta inserção. Ainda, as formas de avaliação adotadas, bem como as estratégias para superar as dificuldades presentes no processo ensino-aprendizagem, de maneira a incluir a família, exigem que as escolas insiram essa discussão no projeto pedagógico, como forma de assegurar a sua compreensão e efetivar a participação dos pais que é ainda um ponto crítico na esfera educacional. Com isso, pode-se romper o estereótipo presente da preocupação centrada apenas nos resultados acadêmicos (Kratochwill, McDonald, Levin, Bear-Tibbetts \& Demaray, 2004).

Além disso, o conhecimento dos valores e práticas educativas que são adotadas em casa, e que se refletem no âmbito escolar e vice-versa, são imprescindíveis para manter a continuidade das ações entre a família e a escola (Keller-Laine, 1998). Sendo assim, as escolas devem procurar inserir no seu projeto pedagógico um espaço para valorizar, reconhecer e trabalhar as práticas educativas familiares e utilizálas como recurso importante nos processos de aprendizagem dos alunos. Mas, a colaboração entre esses contextos deve levar em consideração as diferenças culturais, a formação para cidadania e a valorização de ações e de decisões coletivas (Kratochwill \& cols., 2004; Marques, 2002). As educativas verificadas no âmbito das relações interpessoais e nos resultados acadêmicos dos alunos, têm reflexos na participação efetiva e na integração escola-família, assegurando uma continuidade entre os dois segmentos.

Portanto, as escolas deveriam investir no fortalecimento das associações de pais e mestres, no conselho escolar, dentre outros espaços de participação, de modo a propiciar a articulação da família com 
a comunidade, estabelecendo relações mais próximas. A adoção de estratégias que permitam aos pais acompanharem as atividades curriculares da escola, beneficiam tanto a escola quanto a família. As investigações de Keller-Laine (1998) e de Sanders e Epstein (1998) enfatizam que é necessário planejar e implementar ações que assegurem as parcerias entre estes dois ambientes, visando a busca de objetivos comuns e de soluções para os desafios enfrentados pela sociedade e pela comunidade escolar.

\section{Considerações finais: desafios e perspectivas}

A família não é o único contexto em que a criança tem oportunidade de experienciar e ampliar seu repertório como sujeito de aprendizagem e desenvolvimento. A escola também tem sua parcela de contribuição no desenvolvimento do indivíduo, mais especificamente na aquisição do saber culturalmente organizado em suas distintas áreas de conhecimento. Como destaca Szymanski (2001), a ação educativa da escola e da família apresenta nuances distintas quanto aos objetivos, conteúdos, métodos e questões interligadas à afetividade, bem como quanto às interações e contextos diversificados.

$\mathrm{Na}$ escola, as crianças investem seu tempo e se envolvem em atividades diferenciadas ligadas às tarefas formais (pesquisa, leitura dirigida) e aos informais de aprendizagem (hora do recreio, excursões, atividades de lazer). Contudo, neste ambiente, o atendimento às necessidades cognitivas, psicológicas, sociais e culturais é realizado de maneira mais estruturada e pedagógica do que no de casa. As práticas educativas escolares têm também um cunho eminentemente social, uma vez que permitem a ampliação e inserção dos indivíduos como cidadãos e protagonistas da história e da sociedade. A educação em seu sentido amplo torna-se um instrumento importantíssimo para enfrentar os desafios do mundo globalizado e tecnológico.

Apesar da complexidade e dos desafios que a escola enfrenta, não se pode deixar de reconhecer que os seus recursos são indispensáveis para a formação global do indivíduo. Conhecendo a escola e suas funções, devem-se acionar fontes promotoras de saúde tais como as redes sociais com a comunidade escolar, os profissionais da escola - psicólogos, pedagogos e orientadores educacionais, que são gabaritados (ou deveriam ser) para realizar intervenções coletivas. É nesse espaço que as reflexões sobre os processos de ensino-aprendizagem e as dificuldades que surgem em sala ou em casa são realizadas (Rocha, Marcelo \& Pereira, 2002; Soares, Ávila \& Salvetti, 2000).

Entretanto, como sublinham Soares e cols (2000), apesar de a escola desenvolver aspectos inerentes à socialização das pessoas e ser responsável pela construção, elaboração e difusão do conhecimento, ela vem passando por crises vindas do cotidiano, que geram conflitos e descontinuidades como a violência, o insucesso escolar, a exclusão, a evasão e a falta de apoio da comunidade e da família, entre outros. Neste caso, o cenário político passa a exercer uma influência preponderante para a solução das crises, que extrapolam o cotidiano das escolas. Para superar os desafios que enfrentam, hoje, uma das alternativas é promover a colaboração entre escola e família (Polonia \& Dessen, 2005), tarefa complexa que tem despertado o interesse de vários pesquisadores.

A família e a escola constituem os dois principais ambientes de desenvolvimento humano nas sociedades ocidentais contemporâneas. Assim, é fundamental que sejam implementadas políticas que assegurem a aproximação entre os dois contextos, de maneira a reconhecer suas peculiaridades e também similaridades, sobretudo no tocante aos processos de desenvolvimento e aprendizagem, não só em relação ao aluno, mas também a todas as pessoas envolvidas.

\section{Referências}

Almeida, L. R. (2000). Wallon e a educação. In A. A. Mahoney, \& L. R. Almeida (Orgs.), Henri Wallon: Psicologia e Educação (pp.71-87). São Paulo: Loyola.

Amazonas, M. C. L. A., Damasceno, P. R., Terto, L. M. S., \& Silva, R. R. (2003). Arranjos familiares de crianças de camadas populares. Psicologia em Estudo, 8(especial), 11-20.

Booth, C. L., Rubin, K. H., \& Rose-Krasnor, L. (1998). Perceptions of emotional support from mothers and friends in middle childhood: Links with social-emotional adaptation and preschool attachment security. Child Development, 69(21), 427-442. 
Campos, H. R., \& Francischini, R. (2003). Trabalho infantil produtivo e desenvolvimento humano. Psicologia em Estudo, 8(11), 119-129.

Carneiro, M. A. (2003). LDB fácil: Leitura críticocompreensiva artigo a artigo $\left(9^{\mathrm{a}} \mathrm{ed}\right.$.). Petrópolis: Vozes. (Original publicado em 1998).

Chaves, A. M., Cabral, A., Ramos, A. E., Lordelo, L., \& Mascarenhas, R. (2002). Representação social de mães acerca da família. Revista Brasileira de Crescimento e Desenvolvimento Humano, 12(1), 1-8.

Chaves, A. M., Guirra, R. C., Borrione, R. T. M., \& Simões, F.G.A. (2003). Significados de proteção a meninas pobres da Bahia do século XIX. Psicologia em Estudo, 8(especial), 85-95.

Davies, D., Marques, R., \& Silva, P. (1997). Os professores e as famílias: A colaboração possível ( $2^{\mathrm{a}}$ ed.). Lisboa: Livros Horizontes.

Dell'Aglio, D. D., \& Hutz, C. S. (2002). Estratégias de coping de crianças e adolescentes em eventos estressantes com pares e adultos. PsicologiaUSP, 13(2), 203-225.

Del Prette, A., \& Del Prette, Z. A. P. (2001). Psicologia das relações interpessoais: Vivência para o trabalho em grupo. Petrópolis: Vozes.

Desland, R., \& Bertrand, R. (2005). Motivation of parent involvement in secondary-level schooling. The Journal of Education Research, 3, 164-175.

Dessen, M. A. (1997). Desenvolvimento familiar: Transição de um sistema triádico para poliádico. Temas em Psicologia, 3, 51-61.

Dessen, M. A., \& Braz, M. P. (2000). Rede social de apoio durante transições familiares decorrentes do nascimento de filhos. Psicologia: Teoria e Pesquisa, 16(3), 221-231.

Dessen, M. A., \& Braz, M. P. (2005). As relações maritais e sua influência nas relações parentais: implicações para o desenvolvimento da criança. In M. A. Dessen \& A. L. Costa Junior (Orgs.), A ciência do desenvolvimento humano: Tendências atuais e perspectivas futuras (pp. 132-151). Porto Alegre: Artmed Editora S.A.
Dessen, M. A., \& Pereira-Silva, N. L. (2004). A família e os programas de intervenção: Tendências atuais. In E. G. Mendes, M. A. Almeida \& L. C. A. Williams (Orgs.), Temas em educação especial: Avanços recentes (pp. 179-187). São Carlos: EDUFSCAR.

Eisenberg, N., Fabes, F. A., Shepard, S. A., Guthrie, I. K., Murphy, B. C., \& Reiser, M. (1999). Parental reactions to children's negative emotions: Longitudinal relations to quality of children's social functioning. Child Development, 70(21), 513-534.

Fantuzzo, J., Tighe, E., \& Childs, S. (2000). Family involvement questionnaire: A multivariate assessment of family participation in early childhood education. Journal of Educational Psychology, 92(2), 367-376.

Ferreira, M. C. T., \& Marturano, E. M. (2002). Ambiente familiar e os problemas de comportamento apresentados por crianças com baixo desempenho escolar. Psicologia: Reflexão e Crítica, 15, 35-44.

Fitzpatrick, K. M., \& Yoles, W. C. (1992). Policy, school structure, and sociodemographic effects on statewide high school dropout rates. Sociology of Education, 65, 76-93.

Hedeggard, M. (2002). A zona de desenvolvimento proximal como base para o ensino. In H. Daniels (Org.), Uma introdução a Vygotsky (pp. 199228). São Paulo: Loyola

Keller-Laine, K. (1998). Parents as partners in schooling: The current state of affairs. Childhood Education, 74, 342-345.

Kratochwill, T. R., McDonald, L., Levin, J. R., BearTibbetts, H. Y., \& Demaray, M. K. (2004). Families and school together: An experimental analysis of parent-mediated multi-family group program for American Indian children. Journal of School Psychology, 42, 359-383.

Kreppner, K. (1992). Developing in a developing context: Rethinking the family's role for children development. In L. T. Winegar \& J. Valsiner (Orgs.), Children's development within social context (pp. 161-179). Hillsdale: Lawrence Elbaum Associates. 
Kreppner, K. (2000). The child and the family: Interdependence in developmental pathways. Psicologia: Teoria e Pesquisa, 16(1), 11-22.

Mahoney, A. A. (2002). Contribuições de H. Wallon para a reflexão sobre as questões educacionais. In V.S. Placco (Org.), Psicologia \& Educação: Revendo contribuições (pp. 9-32). São Paulo: Educ.

Marques, R. (2001). Professores, família e projecto educativo. Porto, PT: Asa Editores.

Marques, R. (2002). O envolvimento das famílias no processo educativo: Resultados de um estudo em cinco países. Retirado em 16 de maio 2003, de http://www.eses.pt/usr/Ramiro/ Texto.htm.

Ministério da Educação, Secretaria de Educação Fundamental-MEC/SEF (2001). Parâmetros curriculares nacionais: Terceiro e quarto ciclo, apresentação dos temas transversais. Brasília: Autor.

Oliveira, Z. M. R. (2000). Interações sociais e desenvolvimento: A perspectiva sociohistórica. Caderno do CEDES, 20, 62-77.

Oliveira, M. L.S., \& Bastos, A. C. S. (2000). Práticas de atenção à saúde no contexto familiar: Um estudo comparativo de casos. Psicologia: Reflexão e Crítica, 13(1), 97-107.

Oliveira, E. A., Marin, A. H., Pires, F. B., Frizzo, G. B., Ravanello, C., \& Rossato, C. (2002). Estilos parentais autoritário e democrático-recíproco intergeracionais, conflito conjugal e comportamento de externalização e internalização. Psicologia: Reflexão e Crítica, 15(1), 1-11.

Petzold, M. (1996). The psychological definition of "the family". In M. Cusinato (Org.), Research on family: Resources and needs across the world (pp. 25-44). Milão: LED-Edicioni Universitarie.

Polônia, A. C., \& Dessen, M. A. (2005). Em busca de uma compreensão das relações entre família e escola. Psicologia Escolar e Educacional, 9(2), 303-312.
Rego, T. C. (2003). Memórias de escola: Cultura escolar e constituição de singularidades. Petrópolis, RJ: Vozes.

Rocha, D. G., Marcelo, V. C., \& Pereira, I. M. T. B. (2002). Escola promotora de saúde: Uma construção interdisciplinar e intersetorial. Revista Brasileira de Crescimento e Desenvolvimento Humano, 12, 57-63.

Sanders, M. G., \& Epstein, J. L. (1998). International perspectives on School, Family and community Parternships. Childhood Education, 74(6), 340-341.

Soares, C. B., Ávila, L. K., \& Salvetti, M. G. (2000). Necessidades de saúde de adolescentes do D. A. Raposo Tavares, SP, referidas à família, escola e bairro. Revista Brasileira de Crescimento e Desenvolvimento Humano, 10(2), 19-34.

Stratton, P. (2003). Contemporary families as contexts for development. In J. Valsiner \& K. Connolly (Orgs.), Handbook of developmental psychology (pp. 333-357). London: Sage.

Szymanski, H. (2001). A relação família-escola: Desafios e perspectivas. Brasília: Plano.

Távora, M. T. (2003). Evolução e crescimento de pais e filhos: Mudanças necessárias nessa relação. PSICO 34(1), 23-38.

Volling, B. L., \& Elins, J. (1998). Family relationships and children's emotional adjustment as correlates of maternal and paternal differential treatment: A replication with toddler and preschool siblings. Child Development, 69(6), 1640-1656.

Wagner, A., Halpern, S.C., \& Bornholdt, E.A. (1999). Configuração e estrutura familiar: Um estudo comparativo entre famílias originais e reconstituídas. PSICO, 30, 63-74.

Wagner, A., Ribeiro, L. S., Arteche, A. X., \& Bornholdt, E. A. (1999). Configuração familiar e o bem-estar psicológico dos adolescentes. Psicologia: Reflexão e Crítica, 12(1), 147-156.

Endereço para correspondência:

Maria Auxiliadora Dessen, Universidade de Brasília, Campus Universitário ‘Darcy Ribeiro', Ins- 
32 Paidéia, 2007, 17(36), 21-32

tituto de Psicologia, Departamento de Psicologia Escolar e do Desenvolvimento/PED, Laboratório de Desenvolvimento Familiar. CEP: 70910-000, BrasíliaDF, Brasil. E-mail: dessen@unb.br

Artigo recebido em 03/08/2006.

Aceito para publicação em 08/05/2007.

Este trabalho é baseado na Tese de Doutorado apresentada ao Instituto de Psicologia da Universidade de Brasília, pela segunda autora, sob a orientação da primeira.

Agradecemos as sugestões dadas por Adriane C. Szelbracikoswki à versão preliminar deste artigo. 